$N 6629350^{\circ}$

$\frac{\text { (ACCESSION NUMBER) }}{\text { (PAGES }}$

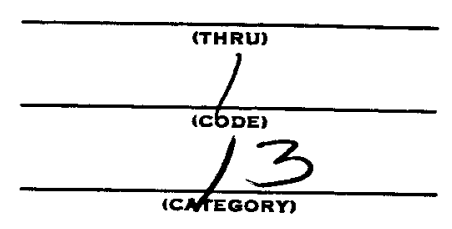

POSITIVE ION COMPOSITION IN THE MAGNETOIONOSPHERE OBTAINED

FROM THE OGO-A SATELLITE

by

H. A. Taylor, Jr., H. C. Briton, and C. R. Smith

GPO PRICE $\boldsymbol{S}$

CFSTI PRICE(S) $\mathbf{S}$

June 29, 1965

Hard copy (HC) 2,00

Microfiche (MF)

.50

f 653 July 85

AERONOMY AND METEOROLOGY DIVISION

GODDARD SPACE FLIGHT CENTER 
Positive Ion Composition in the Magnetoionosphere Obtained

From the OGO-A Satellite

- $A \underline{B} \underline{S} I \underline{R} \underline{A} I$

First results from the $060-A$ positive ion spectrometer experiment are

presented for the period September 23 through December 10, 1964. Thermal

hydrogen and helium ion distributions extend from the lowest observations

at $1500 \mathrm{~km}$ to an altitude of $30,000 \mathrm{~km}$. The density obtained for $\mathrm{H}^{+}$at

$2000 \mathrm{~km}$ is of the order of $10^{3}$ ions $/ \mathrm{cm}^{3}$ and the $\mathrm{He}^{+}$concentration is $1 \%$ of

$\mathrm{H}^{+}$over most of the altitude range. While the concentration and distribution

of $\mathrm{H}^{+}$observed at the lower altitudes is in general agreement with theoretical

models, the upper altitude profiles show signiticant departure from existing

predictions. Evidence is presented which indicates that diffusion of ions is

controlled by the geomagnetic field and that the ions are distributed in a belt-

like region which exhibits a sharp gradient resulting in a 'plateau' at its outer boundary, which is characterized by a reduction in both the $\mathrm{H}^{+}$and $\mathrm{He}^{+}$concentrations of a factor of 10 or more. The ion belt is observed to expand and contract over an altitude range of 8000 to $30,000 \mathrm{~km}$ in an inverse relationship with

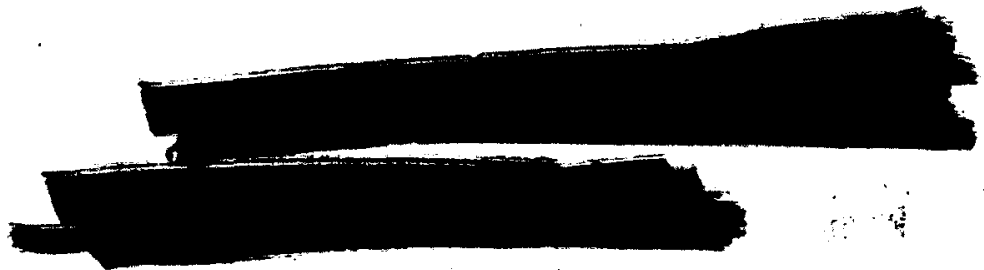


SUBJECT CATEGORIES FOR GODDARD JOURNAL

(To be used for classifying all NASA publications, journal articles, and other papers for inclusion in the Goddard Journal.)

Part A - Space Sciences

$\because \therefore \quad$ A 1 . Astronomy and Astrophysics

A 2. Celestial Mechanics and Geodesy

A 3. Solar Physics

A 4. Ionosphere and Radio Physics

A 5. Fields and Particles

A 6. Planetology

A 7. Planetary Atmospheres

A 8. General (subjects not clearly belonging in any of categories 1-7)

Part B - Space Technology

B 1. Projects and Programs

B 2. Space Dynamics and Control Systems

B 3. Spacecraft and Subsystems

B 4. Vehicle Technology

B 5. Sounding Rockets

B 6. Sensors

B 7. General Electronics

B 8. Environmental Testing

B 9. Tracking Systems

$B$ 10. General (subjects not clearly belonging in any of categories 1-9) 
the magnetic activity index $A_{p}$. There is significant correlation between these results and the knee whistler observations as well as with high altitude ionization

gradients observed from other satellites. Although the data provide some indication of a direct coupling between the lower and upper ionosphere, more data will be required to adequately describe this relationship. 
Introduction

Background

At 0217 GMT on September 5, 1964, the first Orbiting Geophysical Observatory $(0 G 0-A)$ [Ludwig, 1963] was injected into an orb it with an inclination of 31.15 degrees and a period of approximately 64 hours. The orbit had an initial perigee of $282 \mathrm{~km}$ and an apogee of $149,000 \mathrm{~km}$. The spacecraft carried two Bennett radiofrequency mass spectrometers instrumented to measure thermal positive ion composition in the mass range from 1 to 45 AMU. A photograph of the mass spectrometer is shown Fig. 1)

in Figure 1. One spectrometer was designed to measure ions in the range from

1 to 6 AMU while the other sampled ions in the range from 7 to 45 AMU. The successful operation of this instrument provides the first opportunity for high resolution direct measurement of positive ion composition from an altitude of less than $1000 \mathrm{~km}$ to interplanetary space and beyond the boundary of the magnetosphere. This paper is a preliminary report of the low mass data obtained for the three-month period from launch through mid-December, 1964. As a result of difficulties encountered in obtaining very low altitude data the search for high'mass ion has been greatly limited, and accordingly no high mass data are presented. 
Ion Spectrometer Instrument

The ceramic radio-frequency spectrometers flown aboard OGO-A are similar in operation to those flown by.Toyilor and Brinton [1961] and Taylor et al. [1963].

The improved construction techniques and operation of the spectrometer have been described previously [Taylor et al., 1962]. However, several basic features of the supporting electronics, being more sophisticated, are herein described to enable a better understanding of the measurement. These improvements influence the basic operation of the instrument and the frequency of data collectión.

A block diagram of the spectrometer system including appropriate spacecraft functions is shown in Figure 2. The low mass spectrometer is a three stage 5-3 cycle tube with a resolution of 0.5 AMU. The high mass spectrometer is a three stage 7-5 cycle tube with a resolution of 1 in 20 AMU. The positive ion currents detected by each of the spectrometer tubes are measured two

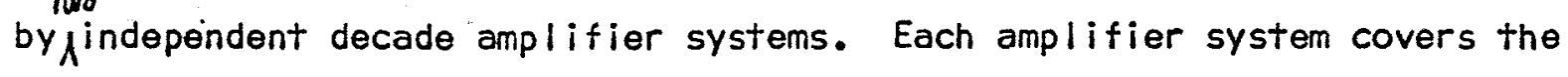
current sensitivity range of $10^{-9}$ to $10^{-14}$ amperes, and provides six simultaneous decade outputs. A synchronous detection system is employed which analyzes the ac component of the detected ion beam after it has been modulated by a 155 cps signal. This prevents the spectrometers from being sensitive to 
the dc effect of photoemission. In addition to the primary signals described above, important parametric voltages are also telemetered.

As shown in the block diagram, an external plate and grid assembly $\left(G_{1}\right)$ was placed in front of the spectrometer system to serve as a guard $r$ ing. The potential on this ring can be programmed by ground command to levels of 0 , $-5,-10$, and -15 volts. The purpose of the guard ring is to present a uniform field at the orifice to eliminate fringing field irregularities and also to serve as a 'drawing-in' grid. The data presented in this paper were obtained with a $G_{1}$ of -15 volts. The remaining two voltages to be discussed are the sweep, $V_{a}$, and the retarding potential, $V_{s}$. The sweep is a sawtooth. wave which provides a negative accelerating potential used in analyzing the ions. The duration of the sweep is such that the same ion is sampled once each 64 seconds, resulting in a spatial resolution of approximately $300 \mathrm{~km}$ of altitude. The retarding potential, a dc voltage which controls the sensitivity of the spectrometer, automatically steps to a new level once each sweep, through a series of four levels. The range of these levels can be adjusted by ground command. It is emphasized that the data presented in th is paper were obtained with a constant $V_{s}$ range. 
Additional ground commands also provide passive calibration of the amplifier systems. In-flight calibration data and voltage monitor data indicate that after 5000 hours of operation, afl critical voltage levels remain with in laboratory calibration specitications, which gives the authors added confidence in the reliability of the data presented here. Instrument Location and Orientation

As shown in Figure 3, the experiment was mounted in the Orbit Plane Experiment Package (OPEP) No. I which was intended to look at all times into the orbit plane. Due to a failure in the attitude control system, however, the spacecraft spun about the $Z$ axis with a 12-second period. This failure necessitated the the OPEP be 'locked in' and remain stationary with respect to the spacecraft body. In this position, the normal to the spectrometer orifice makes a constant angle of approximately $90^{\circ}$ with the spacecraft spin axis. For the altitude range covered by the data, the minimum angle between the spacecraft velocity vector and the spectrometer orifice normal varies from approximately $30^{\circ}$ at high altitudes to $90^{\circ}$ at perigee.

\section{Data Coverage}

This paper is concerned with the presentation and discussion of the $\mathrm{H}^{+}$. and $\mathrm{He}^{+}$distributions for a total of 15 passes obtained during the three-month per- 
lod between September 23 and December 10, 1964. During this period, the local time of perigee varied from approximately 0800 to 0300 hours, while the minimum angle between the earth-sun line and the orbit plane varied from $7^{\circ}$ to $54^{\circ}$. As a result, the inbound data were obtained on the night side of the earth, while the outbound data were obtained on the day side.

The phasing between the 060-A orbit period and the earth's rotation caused data to be obtained when the spacecraft was above three distinct grographical (Fig.4 locations, as illustrated in Figure 4. These locations, or groups, are identified with the stations from which the data were obtained. This method of labeling is used primarily for convenience and does not specifically associate the data geophysically with the location of the recording station. .

The gravitational influence of the sun and moon on the satellite orbit caused the perigee height to increase from $282 \mathrm{~km}$ at launch to approximately $1000 \mathrm{~km}$ by October 7, 1964. As a result, the data presented were obtained above $1000 \mathrm{~km}$ and extend to varying altitudes, the highest being $30,000 \mathrm{~km}$.

\section{$\underline{\text { Results }}$}

\section{Uncorrected Ion Data}

A typical example of the ion spectra which were obtained on OGO-A is shown (Fig.5) in Figure 5, indicating clearly the resolution that was obtained. It should be 
noted that the small spikes which appear on the spectrum were caused by interference from with in the spacecraft. No ion peaks other than $\mathrm{H}^{+}$and $\mathrm{He}^{+}$have been observed in the low mass data studied thus far.

The ion currents Ic measured at the collector of the low mass spectrometer on successive sweeps during an incoming realtime pass of the satellite on October 31, 1964, are plotted in Figure 6. Smoothed Ion Data

The scatter in the data points for both masses in Figure 6 is caused primarily by two effects. One effect results from the changing aspect of the spectrometer orifice with respect to the velocity vector, caused by the spacecraft spin. The second effect is due to the automatic stepping of the $V_{s}$ with in the spectrometer tube. By normalizing the raw data to (1) a single spin plane aspect angle and (2) a single $V_{5}$ level, much of the scatter may be removed from the data points in Figure 6. Figure 7 demonstrates the technique used to evaluate the magnitude of the two effects. In this figure are plotted the $\mathrm{H}^{+}$ion currents for the four $V_{s}$ levels in the altitude range from $2700 \mathrm{~km}$ to $11,500 \mathrm{~km}$ on the October 31 pass. The normal to the spectrometer orifice sweeps through an angle of $360^{\circ}$ in the spin plane during each spacecraft spin period. To generate Figure 7 an arbitrary $0^{\circ}$ direction was 
chosen for the $\mathrm{H}^{+}$peak occurring at $2700 \mathrm{~km}$ altitude and the spin plane angle relative to this direction was calculated for each successive $\mathrm{H}^{+}$peak. It is apparent from this figure that the ion current collected by the spectrometer varied with aspect in the spin plane by approximately a factor of 10. At the same time the programmed changes in internal spectrometer sensitivity $\left(V_{s}\right)$ varied the collected current by approximately a factor of two.

Because of the altitude variation of spacecraft velocity, and attitude and effective $V_{s}$ (discussed later), it was necessary to generate curves similar to Figure 7 for the remainder of the altitude range covered by the October 31 data. Figure 8 shows the corrected $\mathrm{H}^{+}{ }^{\text {and }}$ data $\mathrm{He}^{+}$ techniques to the data of Figure 6 . Smooth curves have been drawn through the corrected $\mathrm{H}^{+}$and $\mathrm{He}^{+}$points. It has been determined that these curves approximate the running averages of the original uncorrected points. For this reason the remaining ion distributions for both $\mathrm{H}^{+}$and $\mathrm{He}^{+}$will be represented by smooth running averages. It may be assumed that the aspect effect is caused by either spacecraft velocity or a directed flow of ions in space. The former explanation is supported by the observation that the envelope of the $\mathrm{He}^{+}$points in Figure 6 is wider than the envelope of the $\mathrm{H}^{+}$points, as one might expect considering the $\therefore \therefore \therefore \approx 0$ 
difference in mass and hence the velocity of the helium and hydrogen ions.

It has not been determined that the relative angle producing maximum sensitivity in Figure 7 corresponds to the position of the OPEP for which the angle between the spectraneter orifice normal and the spacecraft velocity vector is a minimum. It this is the case, however, the previous discussion relative to the envelope width suggests that the ion temperature is in the $\because \cdots$, thermal range.

Another variable which influences the ion current measurements is the spacecraft potential. Since $V_{s}$ is referenced to spacecraft ground its value effective varies with any changes in the reference voltage. Further, it is believed that changing spacecraft potential may affect the collection area of the spectrometer orifice, although this is believed to be a minor effect. From analysis of the ion spectra, considering harmonic ion peak sensitivity and position [Johnson, 1958], there is evidence that the spacecraft potential varied from approximately -15 volts at low altitudes to zero volts at high altitudes. The mechanism suggested as the source for this potential is the probe action of the exposed positive electrodes of the spacecraft solar cells. Since this negative charge mechanism opposes the positive potential induced by photoemission, the observed decrease in neg- 
ative spacecraft potential with altitude is consistent with a corresponding decrease in ambient ion density. It is significant that gradients in the $\mathrm{H}^{+}$and $\mathrm{He}^{+}$currents, such as those shown above $19,000 \mathrm{~km}$ in Figure 8 , are observed repeatedly. Even though the exact magnitudes of these changes are difficult to determine due to the changing influence of spacecraft potential, we have no doubt that the current gradients result from real decreases in ambient ion density.

\section{Current to Density Conversion}

The precise conversion of raw ion current to ambient ion density is a rim

most difficult problem that has not been adequately solved. Quantitative

consideration of the effects of spacecraft potential, vehicle velocity, and

details of the spectrometer-plasma interface can only be accomplished when

these parameters are well understood and completely defined. Such a treatment

is beyond the scope of this preliminary report. However, to obtain a best es-

timate of the ion current-to-ion density conversion factor an approximate cal-

culation was carried out which considered the parameters of spectrometer ef-

ficiency, vehicle velocity and orientation, and effective collection area of

the spectrometer orifice. This calculation yielded the result that an ion current

of $10^{-11}$ amperes measured at the spectrometer collector corresponds approximately

to an ambient density of $10^{3}$ ions $j \mathrm{~cm}^{3}$. Based upon this reference density, co- 
ordinates of both ion density $\left(N_{i}\right)$ and ion current $\left(I_{c}\right)$ are presented in Figures 9 through 12. It should be emphasized that the density distributions presented in these figures have been obtained by normalization and that a point-by-point conversion of current to density has not been performed. Ion Distributions versus Altitude

A most important feature which we have consistently observed in the upper altitude ion distribution ${ }_{h}^{5}$ is the presence of sharp gradients which vary in altitude between approximately 8000 and $30,000 \mathrm{~km}$. With respect to altitude. these distributions tend to fall into two general categories, as shown in

Figures 9 and 10. Each of these figures presents $\mathrm{H}^{+}$and $\mathrm{He}^{+}$ion data smoothed in the manner specified for the data in Figure 8.

The ion distributions presented in Figure 9 are typical of the high altitude data which have been repeatedly observed. These concentrations tend to fall off slowly with increasing altitude until, in the range of $25,000 \mathrm{~km}$, the decrease becomes more rapid, resulting in ion plateaus near $30,000 \mathrm{~km}$. These data were obtained at Johannesburg during three incoming nighttime passes of the satellite. On these passes it was possible to obtain data down to perigee at approximately $1500 \mathrm{~km}$. In contrast, we have found that on a comparably significant number of passes the ion plateaus occur at comparatively low altitudes, in the 
range 8000 to $15,000 \mathrm{~km}$. Examples of these lower altitude distributions are shown in Figure 10. Although the low altitude portions of these profiles are similar to corresponding portions of the date in Figure 9, the outstanding characteristic of each of these passes is the dramatic decrease of ion current as a function of altitude. These data were obtained from Rosman during three outgoing daytime passes of the satellite. It was not possible on these passes to 'see' the satellite below approximately $7000 \mathrm{~km}$ and hence data taken below this altitude will only be obtained by analysis of spacecraft tape recorder data. Relative Concentrations of $\mathrm{H}^{+}$and $\mathrm{He}^{+}$

As shown in Figures 9 and 10 the ratio: of $\mathrm{H}^{+}$to $\mathrm{He}^{+}$is cons istently 100 to 1 over most of the altitude range. In the region near $3000 \mathrm{~km}$ on October 15 and 23 , however, the $\mathrm{He}^{+}$current falls gradually to a minimal level but increases again near perigee. This decrease does not appear to be caused by instrumental limitations nor is it accompanied by a change in spacecraft potential.

\section{Ion Distributions versus Magnetic Coordinates}

Figures 11 and 12 present the same ion data shown in Figures 9 and 10 , with the vertical coordinate being Mcllwain's L parameter rather than alti- 
tude. In addition, the ordinate on the right of Figures 11 and 12 is. $\lambda_{L}$, defined as the geomagnetic latitude at which the corresponding $L$ shell on the . left ordinate intersects the surfece of the earth. This parameter is useful when considering the current theories-of magnetospheric control by means of coupling along $L$ shells of the lower ionosphere to the magnetosphere.

1

Interpretation

Correlation with Knee Whistler Observations

The ion distributions shown in Figures 11 and 12, which are typical of much of the data, provide a striking albeit preliminary concept of certain characteristics of the magnetoionosphere. In general, the ion distributions measured in this altitude region exhib th an initial gradual decrease with altitude followed at varying heights by a sudden decrease in density. The amplitude of the decrease or plateau is generally observed to be a factor of 10 or greater, occurring within an altitude range as small as $500 \mathrm{~km}$. These general features, which we have observed in over 20 hydrogen and helium ion current profiles obtained from $0 G O-A$, are very similar to the characteristics of the equatorial electron density profile deduced by Carpenter $[1963]$ from whistler data. The strong correlation in these data is 
Fig.13) Illustrated in Figure 13, in which $\mathrm{H}^{+}$plateaus of November 2 and November 18 (Johannesburg) and September 23 (Rosman) are plotted with a typical knee whistler profile $\left(\mathrm{N}_{e}\right)$ obtained by Carpenter. For simplicity, the $\mathrm{He}^{+}$distributions are not plotted in Figure 13 since on these passes, as well as on all other passes reported, the $\mathrm{He}^{+}$distributions closely parallel those of $H^{+}$.

It is significant that very similar patterns in the distribution of the thermal ion plasma have been observed by Russian experimenters from ion trap measurements on deep space probes $[$ Gringauz et al., 1963] and satellites [Gringauz et al., 1965]. Furthermore, evidence of a sharp gradient in the thermal electron plasma has been reported by Serbu $[1964]$ from the $1 \mathrm{mp}-1$ plasma probe results.

The similarity between the $N_{e}$ and $N_{i}$ profiles of Figure 13 becomes even more significant when one considers that the $N_{i}$ measurements occurred at varying magnetic latitudes (see Figure 4), while the $\mathrm{N}_{e}$ curve defines the ionization distribution along the magnetic equator. This suggests that the characteristic features observed in the ion profiles are widely distributed within the mag- 
netosphere, in a manner which is strongly controlled by the geomagnetic field. Such evidence tends to support the theory that hydrostatic equilibrium exists along magnetic field lines, and implies that ion distributions measured at differing spatial locations may be compared analytically, using techniques such as those proposed by Angerami [1964].

\section{Correlation with Magnet ic Activity}

Another very important feature of Figure 13 is the difference in the $L$ values at which the $N_{i}$ plateaus occur. It is significant that for these passes the magnetic activity index $A_{p}$ varies inversely with the ion plateau $\mathrm{L}$ values. Again these data agree directly with Carpenter's observation that the $L$ coordinate of the whistler knee is decreased during periods of increased magnetic activity.

The apparent correlation with magnetic activity is further supported by the ion data collected throughout the period September through December, 1964. For this period a total of 15 samples representing all passes for which processable data is available, and for which the experiment operating conditions are comparable, have been analyzed. For each pass the coordinates of the satellite at which a significant loss in ion current occurred have 
prior day. In analyzing these data it was determined that the selection of a two-day sample of $A_{p}$ provides the best overall correlation. The choice of the prior day is particulardy appropriate since a number of the passes were recorded during the earliest hours of the day specified for the measurement. With the exception of the passes recorded on November 16 and November 26, the data in Table 1 may be divided into groups of disturbed, moderately disturbed, and quiet magnetic activity, for which the coordinates of ion loss consistently occur in an inverse relationship to the value of $A_{P}$.

The rather dramatic correlation between the magnetic activity and the ion distributions is illustrated graphically in Figure 14. In this graph the trajectories of representative passes are plotted as functions of geocentric distance, magnetic latitude, and $L$. It should be understood that in this plot magnetic longitude and local time variations are not considered and the passes are plotted as if all trajectories were in the same plane. The curve shown for each date is solid up to that altitude at which the ion plateau is observed, and dashed beyond.

Three types of passes are shown, providing examples of data obtained from 
Johannesburg and Rosman on the night side of the orb it, and from Rosman on the day side. It is significant that with in each group of passes the variation of coordinates between passes, is relatively small (less than $5^{\circ}$ of latitude and $10^{\circ}$ of longitude), which permits direct comparison of individual ion distributions within a given group. Comparison of the data shown in Figure 14 provides clear evidence that within each pass group the $L$ coordinate of the transition from gradual to rapid ion density fall-off varies inversely with changes in magnetic activity (see Table 1 for corresponding $A_{p}$ values). This is particularly pronounced in the two nightside data groups, in which greatly different ion profiles are obtained on passes which appear to differ. only in terms of magnetic disturbance.

It is significant that in the period from October 23 to December 10 data recorded at Johannesburg from passes occurring eight days apart are characterized, with the exception of November 24, by high altitude plateais corresponding to low magnetic activity (see Table 1). Since the orbital period of the satellite is such that an eight day cycle occurs in passes over a given station, it is natural to question whether a systematic phasing might develop between the orbital period and changes in the magnetic activity, which would confuse further inter- 
pretation of spatial and local time effects. Such a possibility is closely related to the observations of Ness et al. $[1965]$ of a direct correlation between $K_{p}$ and the elght day cycle in the passoge of sectors of the Archimedean spiral structure of the interplanetary magnetic field. Although the quantity of ion data available to date is not sufficient to permit an extensive examination of such an effect, the dynamic implication involved calls for a cereful analysis of such data at the earliest opportunity.

\section{Local Time Variations}

Because of the strong association apparent between the magnetic activity and the ion profiles, it has not yet been possible to thoroughly separate the effects of $A_{p}$ and local time. However, for at least 10 pairs of inbound and outbound passes obtained during periods of relatively constant magnetic activity, the ion distributions have been observed to be quite similar; in the majority of these cases the altitude plots of inbound and outbound $\mathrm{H}^{+}$and $\mathrm{He}^{+}$ ion currents can be superimposed with negligible disagreement.

The independence of the $\mathrm{H}^{+}$current profiles of local time and magnetic longitude variations is also indicated in Figure 14. Although local time coordinates are not shown specifically, gross local time effects, if they exist, 
should be evident in a comparison of inbound (type A) and outbound (type B) profiles obtained on the same day. It is clear both from this. plot and from Table I that the inbound and outbound regions of $\mathrm{H}^{+}$ion density plateaus occur at similar L coordinates even though the local times of the inbound and outbound measurements are quite different. For the example shown the local time of the November 2 and November 10 inbound $\mathrm{H}^{+}$plateaus was approximately 1200 hours while the local time of the corresponding outbound plateaus was approximately 2000 hours.

\section{Conclusions}

The overall picture gained from these data is one of a belt of thermal ions which appears to expand and contract with changes in magnetic activity. There is strong evidence that with in this belt the distribution of ions is controlled along the lines of the geomagnetic field. The altitude of the sharp gradient which defines the outer boundary of the belt varies inversely with magnetic activity over an altitude range of $8000 \mathrm{~km}$ to $30,000 \mathrm{~km}$. Although the number density of $10^{3}$ ions $/ \mathrm{cm}^{3}$ inferred for $\mathrm{H}^{+}$at the $2000 \mathrm{~km}$ level is in reasonable agreement with the lower altitude portions of models proposed by Johnson $[1960]$, Bates and Patterson. $[1961]$, and Angerami $[1964]$, the ion density gradients observed in the high altitude regions exhibit significant departure 
It is significant that $\mathrm{H}^{+}$and $\mathrm{He}^{+}$have been observed from $1500 \mathrm{~km}$ to $30,000 \mathrm{~km}$ and that the ratio of $\mathrm{H}^{+}$to $\mathrm{He}^{+}$is approximately 100 to 1 over most of the altitude range..

The apparent consistency among the observations of (1) the distribution of ions along magnetic shells (2) the dynamic role of magnetic activity and (3) the possible correlation with variations in the interplanetary magnetic field, leads to the challenging question of whether the indicated expansion and contraction in the observed ion belt results from forces acting both internal and external to the magnetoionosphere. Certainly the observed evidence of geomagnetic control appears to support the argument for direct internal coupling of the lower and upper ionosphere, as suggested by Angerami [1964]. Further, the strong latitude gradients in total ion density at $1000 \mathrm{~km} \mathrm{re-}$ ported by Brace $[1965]$ and by Barrington et al. $[1965]$ may possibly be the source of some of the higher altitude $\mathrm{H}^{+}$and $\mathrm{He}^{+}$gradients if the mechanism of hydrostatic flow along field lines. is effective.

If a case is to be made for predominantly internal control, "the strong relationsjip observed between the ion concentrations and the magnetic activity seems to suggest a mechanism in which, during periods of magnetic disturbance, 
some component of the solar input penetrates to comparatively low latitude regions of the lower ionosphere. The resulting enhanced ionization would then populate magnetic shells of lower $L$ number, resulting in the observed contraction of the outer boundary of the plasma belt. This interpretation seems to bear some relationship to observation and theory. Akasofu [1962] has observed that auroral activity penetrates toward the equator during magnetic storms; Parker [1962] suggests a wagnetospheric model which during magnetic storms calls for dynamic plasma perturbations in the L space of 3 to 5 .

The application of such mechanismito the interpretation of our results must remain preliminary until a more extensive sample of both ion and magnetic data is obtained. It is recognized that a statistical study will be required to enable a meaningful investigation of local time, seasonal, and spatial - parameters required to construct a descriptive empirical model of the magnetoionosphere.

\section{ACKNOWLEDGMENTS}

The authors wish to thank D. L. Carpenter, Dr. J.lWaiker, and L. H. Brace for advice and helpful discussions.

We also wish to acknowledge the devoted contributions of $f$. S. Burcham and $P$. K. Monaghan, who were responsible for the mechanical design and testing 
of the experiment package. Dr. T. C. G. Wagner, G. S. Scholl and associates provided outstanding contributions to the engineering design and calibration of the experiment, and L. Re Muenz, S. C. Crooke, and F. J. Woods were extremely helpful in the reduction and analysis of the data. 


\section{REFERENCES}

Akasofu, S. 1., The changing distribution of the aurora during large magnetic storms, J. Atmosph. Terr. Phys., 24, 723-727, 1962.

Angerami, J. J., and J. O. Thomas, Studies of planetary atmospheres, J. Geophys. Res., 69, 4537-4560, 1964.

Barrington, R. E., J. S. Belrose, and G. L. Nelms, lon composition and temperatures at $1000 \mathrm{~km}$ as deduced from simultaneous observations of a vif plasma resonance and topside sounding data from the Alouette I satellite, J. Geophys. Res., 70, $1647-1664,1965$.

Bates, D.R., and T. N. L. Patterson, Hydrogen atoms and ions in the thermosphere and exosphere, Planetary Space Sci., 5, 257-273, 1961.

Brace, L. H., and B. M. Reddy, Latitudinal variations of electron temperature and concentration from satellite probes, Presented to the Vi-th International Space Sci. Symp., Buenos Aires, May, 1965.

Carpenter, D. L., Whistier evidence of a 'knee' in the magnetospheric ionization density profile, J. Geophys. Res., 68, 1675-1682, 1963.

Gringauz, K. I., V. G. Kurt, V.l. Moroz, and 1. S. Shklovikii, Results of observations of charged particles out to $R=100,000 \mathrm{~km}$, with the aid of charged particlertraps on Soviet space rockets, Astronomicheskii Zhurnal, 37, 716-735, 1960. 
Gringauz, K. I., V. V. Bezrukikh, L. S. Musatov, R. Ye. Rybchinsky, and E. K. Solomatina, Some results of measurements carried out by means of charged particle trap on the Electron-2 satellite, Presented to, the VI-th International Space Sci. Symp., Buenos Aires, May, 1965.

Johnson, C. Y., Mass determination of ions detected by Bennett rf mass spectrometer, J. App I. Phys., 29, 740-741, 1958.

Johnson, F. S., The ion distribution above the $F_{2}$ maximum, J. Geophys. Res., 65, 577, 1960.

Ludwig, G. H., The orbiting geophysical observatories, Space Sci. Rev., 2, $175-218,1963$.

Ness, N. F., C. S. Scearce, J. B. Seek, and J. M. Wilcox, A summary of results from the Imp-l magnetic field experiment, Presented to the VI-th International Space Sci. Symp., Buenos Aires, May, 1965.

Parker, E. N., Dynamics of the geomagnetic storm, Space Sci. Rev., 1, 62$99,1962$.

Serbu, G. P., Results from the Imp-l retarding potential analyzer, Presented to the V-th International Space Sci. Symp., Florence, May, 1964 .

Taylor, H. A., Jr., and H. C. Brinton, Atmospheric ion composition measured above Wallops island, Virginia, J. Geophys. Res., 66, -2587$2588,1961$. 
27

Taylor, H. A., Jr., H. C. Briton, and C. R. Smith, Instrumentation for atmospheric composition measurements, Proc. 8th Ann. AeroSpace Symp., pp. 1-14, Instrument Society of America, Washington, 1962.

Taylor, H. A., Jr., L. H. Brace, H. C. Briton, and C. R. Smith, Direct measurements of helium and hydrogen ion concentration and total ion density to an altitude of 940 kilometers, J. Geophys. Res., 68, 5339-5347, 1963. 


\section{FIGURES}

Fig. I. Ion mass spectrometer instrument flown on OGO-A.

Fig. 2. Block diagram of the ion mass spectrometer system.

Fig. 3. Location of the ion mass spectrometer instrument on OGO-A. Also shown is the spacecraft spin axis $(Z)$.

Fig. 4. Data coverage with respect to geographic latitude and longitude. Inbound and outbound data obtained during the same perigee pass are identified by the letters $A$ and $B$, respectively.

Fig. 5. Photograph of typical hydrogen and helium ion spectra obtained from OGO-A.

Fig. 6. Uncorrected hydrogen and helium ion current data obtained during the pass of October 31, 1964. Occasional gaps in data occur as a result of signal dropout.

Fig. 7. Uncorrected hydrogen ion current detected in the altitude range $2700 \mathrm{~km}$ to $11,500 \mathrm{~km}$ on October 31 , plotted as a function of relative angle in the ion spectrometer spin plane to demonstrate the effect of varying aspect. The currents obtained for each of the four $V_{s}$ levels of spectrometer sentitivity are shown.

Fig. 8. Smooth hydrogen and helium ion current profiles drawn through the points obtained by applying aspect and $v_{\mathbf{s}}$ corrections to the . raw data shown in Figure 6. 
Fig. 9. Hydrogen and helium ion distributions measured during three satellite passes showing gradual fall-off followed in two cases by 'plateaus' at high altitude. The high altitude data for October 15 is incomplete becouse of a deto transmission loss.

Fig.10. Hydrogen and helium ion distributions measured during three satellite passes showing 'plateaus' at low altitude.

Fig.11. Hydrogen and helium ion distributions shown in Figure 9 plotted as functions of Mcllwain's $L$ parameter and $\lambda_{L}$, the gecmagnet ic latitude at which the corresponding $L$ shell intersects the earth.

Fig.12. Hydrogen and helium ion distributions shown in Figure 10 plotted as functions of $L$ and $\lambda_{L}$.

Fig.13. Correlation between three $N_{i}$ plateaus obtained at varying geomagnetic coordinates and the knee in the equatorial profile of $\mathrm{N}_{e}$ determined from whistler data.. The inverse relationship between plateau altitude and $A_{p}$ is demonstrated.

Fig.14. Locations at which significant reduction or loss of $\mathrm{H}^{+}$current was observed during nine satellite passes. The solid portion of each curve indicates a region of gradual decrease in ion current with altitude, while the beginning of the dashed portion specifies the location of rapid decrease in current. Magnetic longitude and local time are not shown in detail, and each pass is plotted as if it occurred in the same plane. The sun arrow indicates the general orientation of the sun during these observations. 
Table 1. Correlation between the coordinates of $\mathrm{H}^{+}$current loss and variation in the magnetic activity index $A_{p}$. Inbound and outbound portions of the same perigee pass are designated $A$ and $B$ respectively. - 
Suggested short title for paper for the heading of the right-hand pages:

Ion Composition of the Magnetoionosphere 


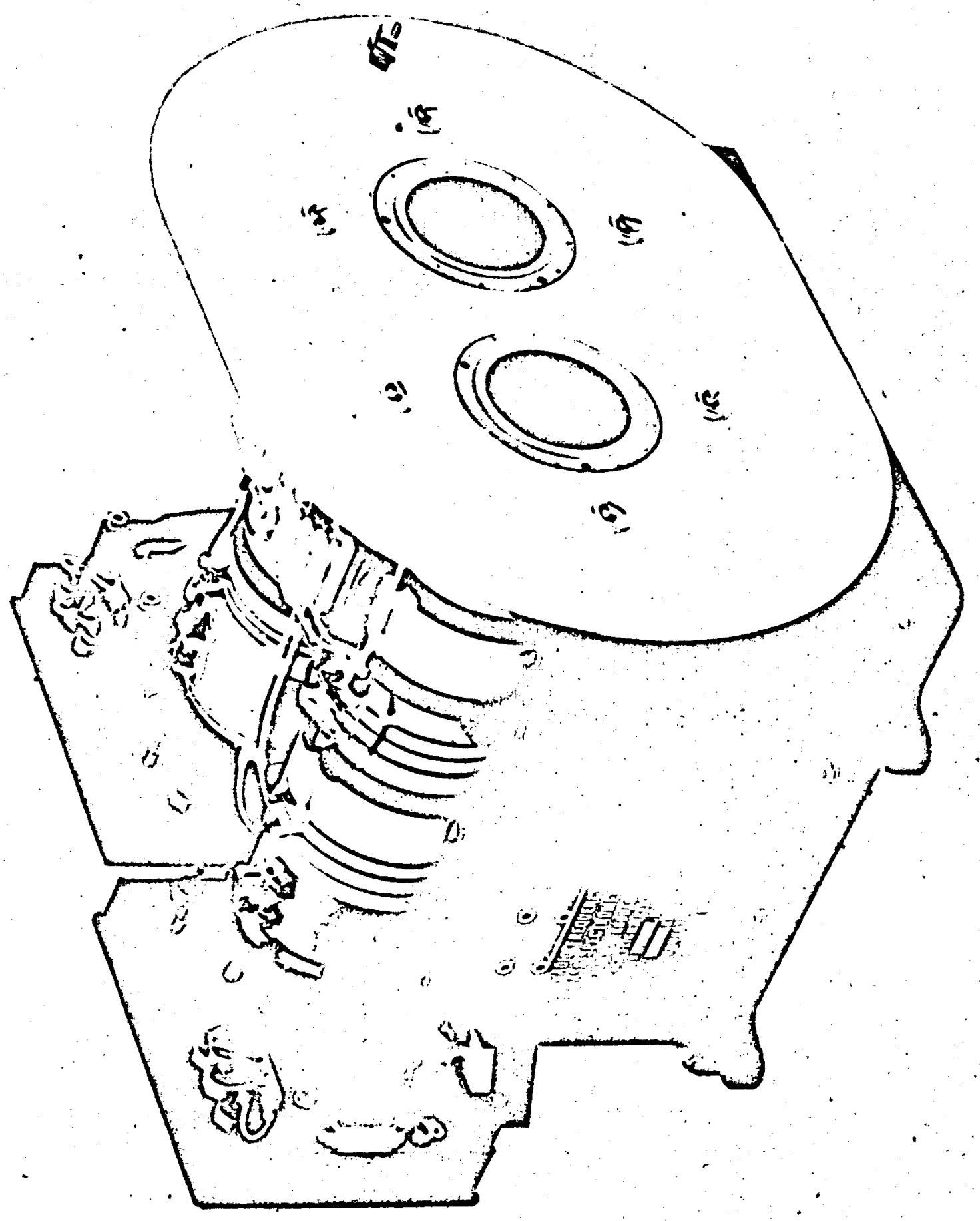

Fig.l 


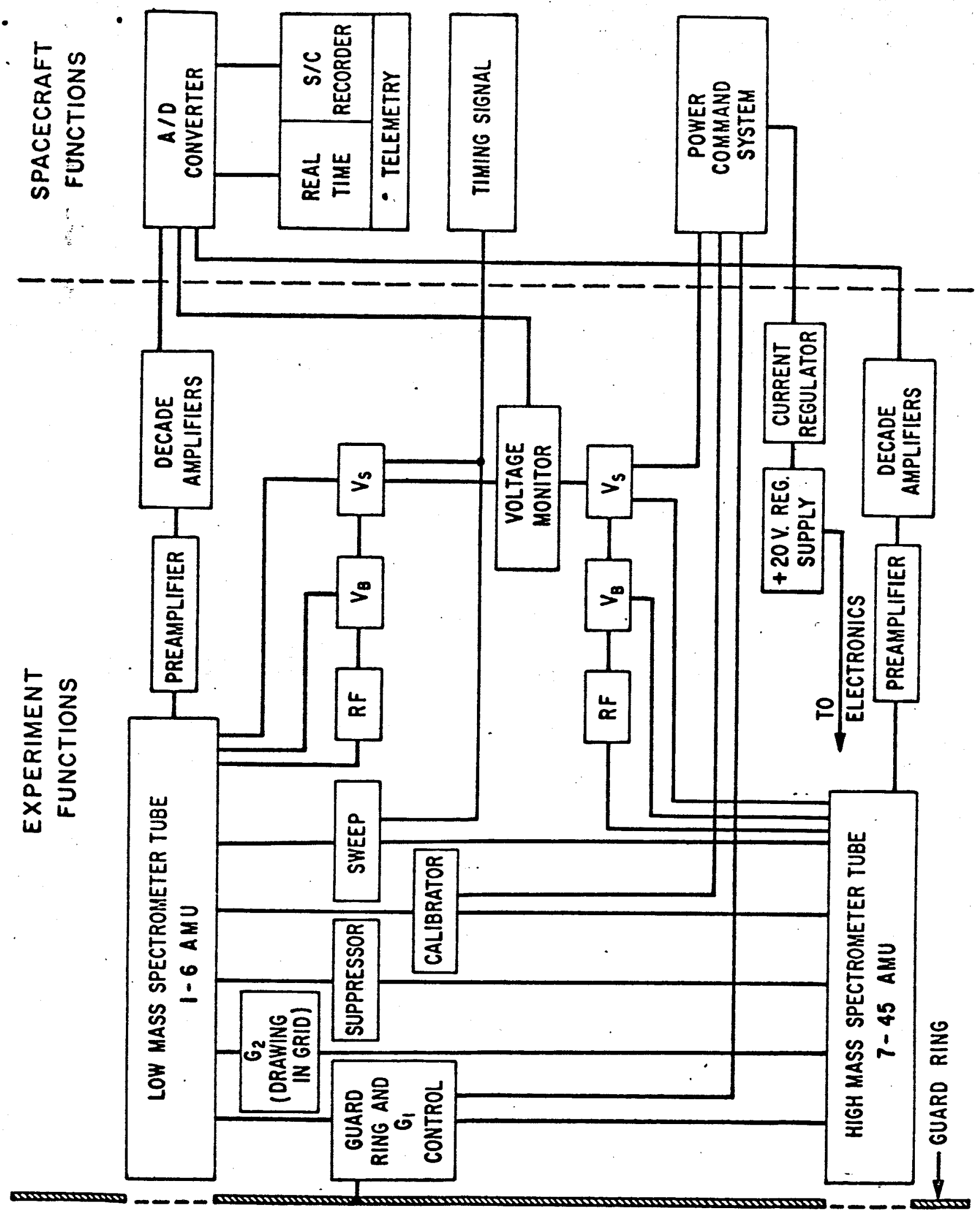

Fig. 2 


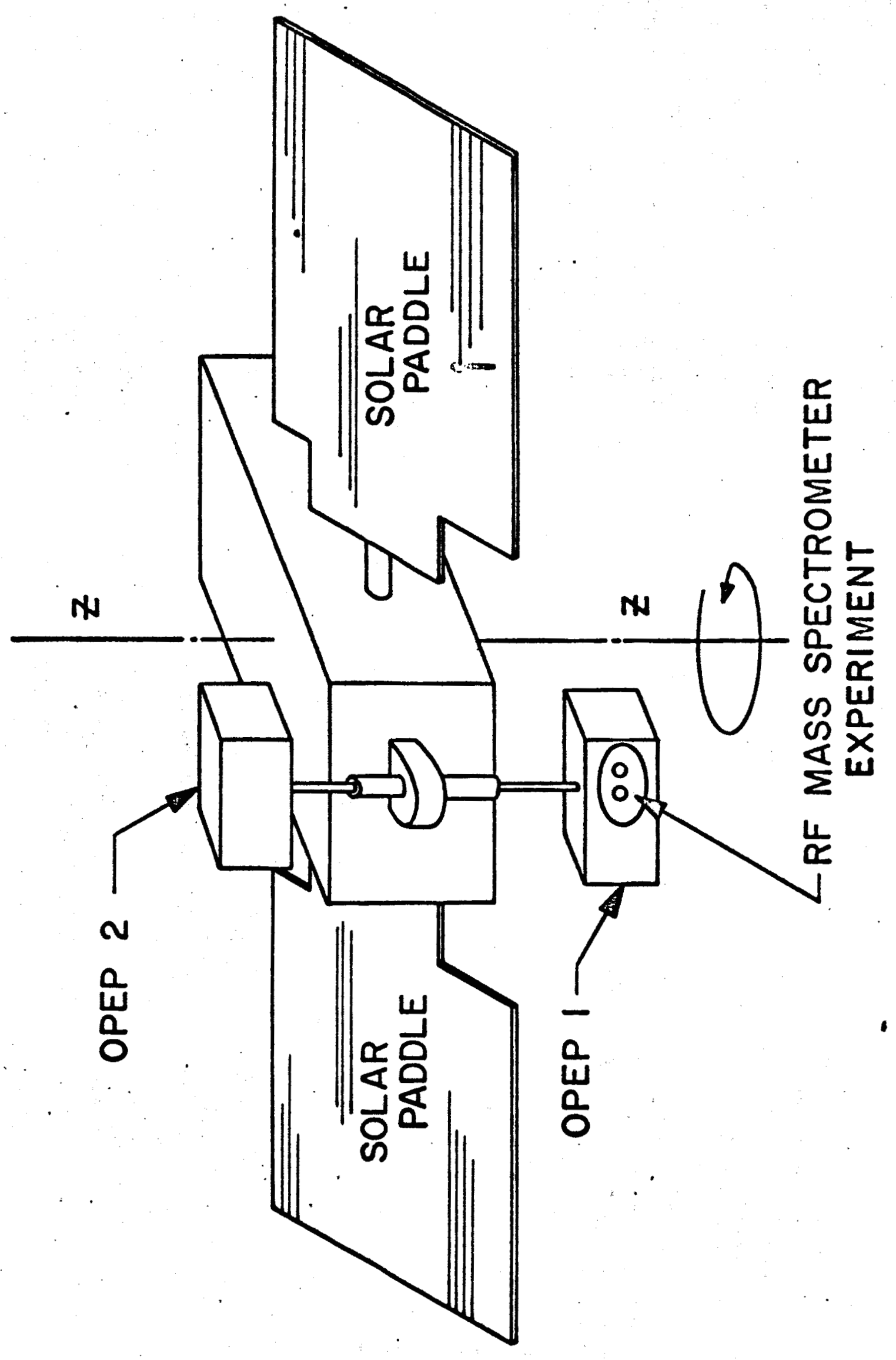

Fin? 


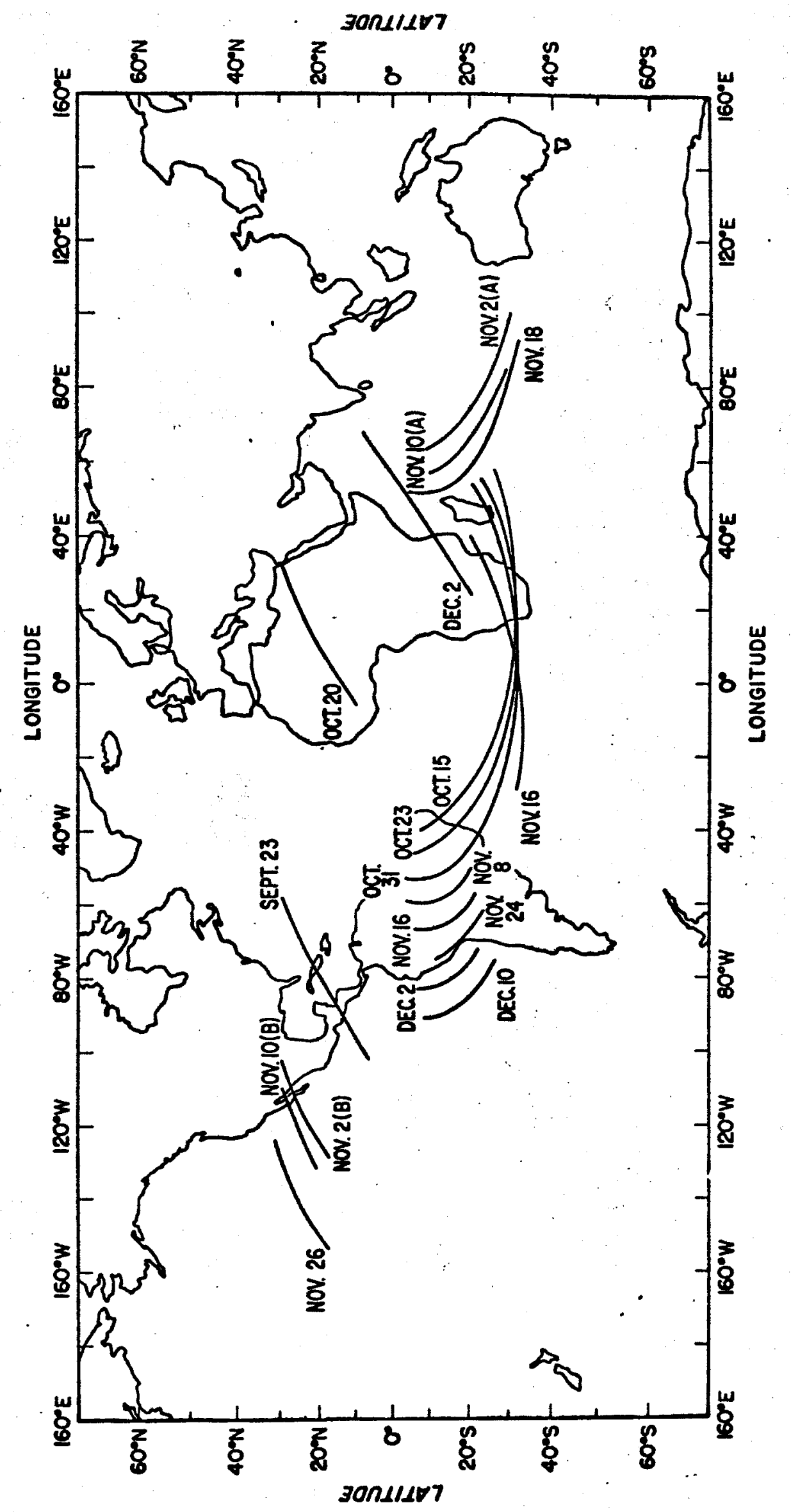

Fin.4 

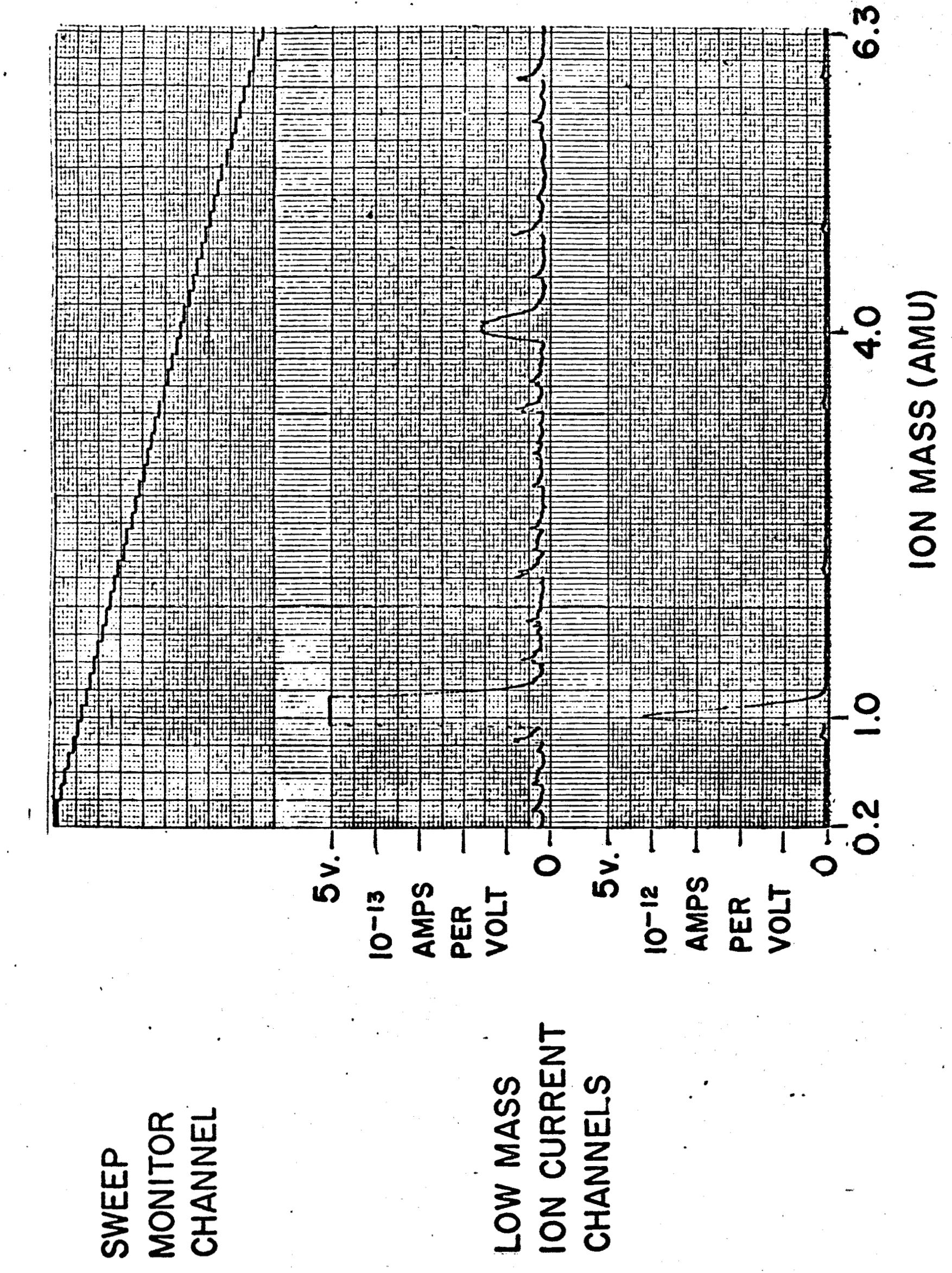


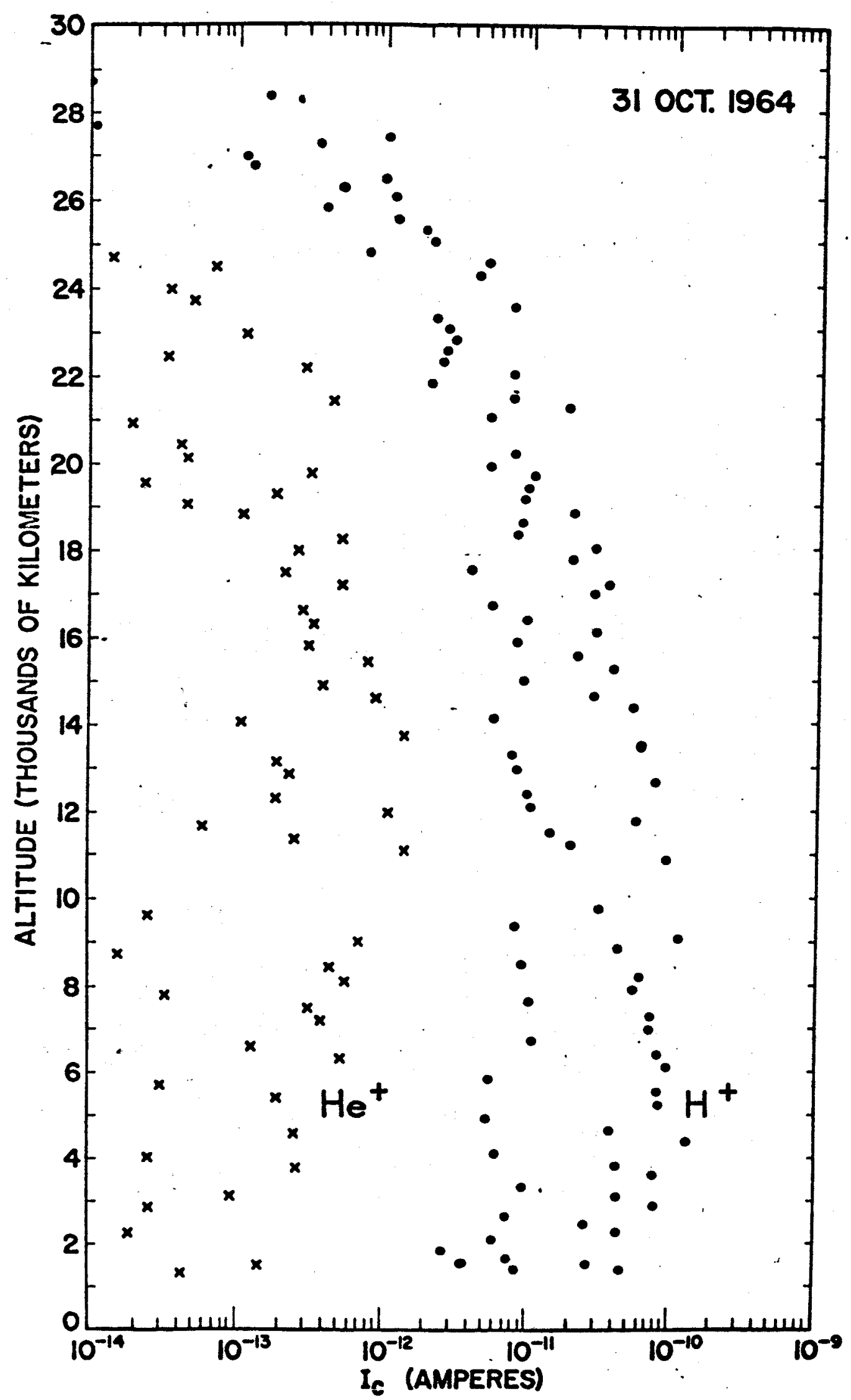




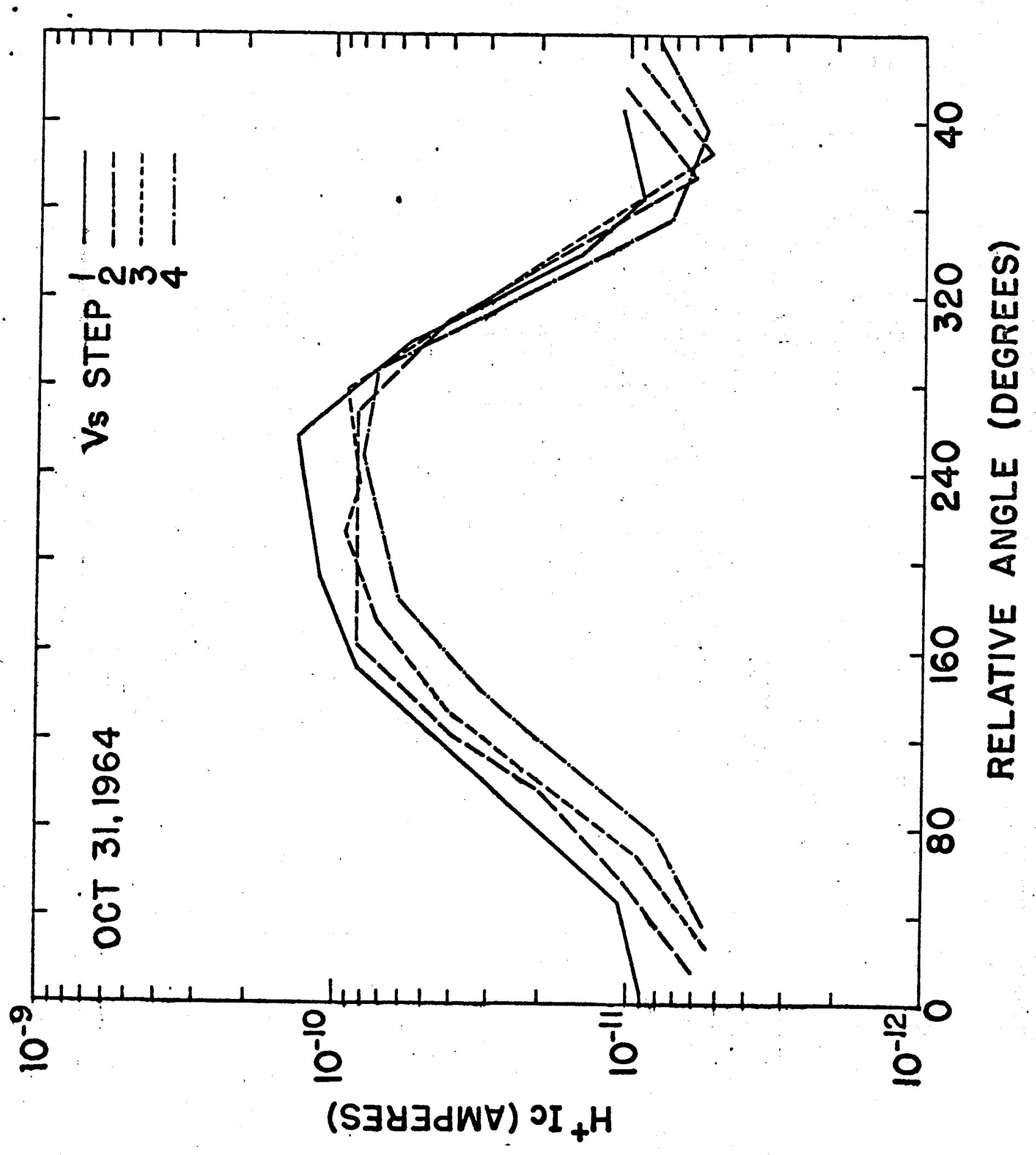

- Fig. 7 


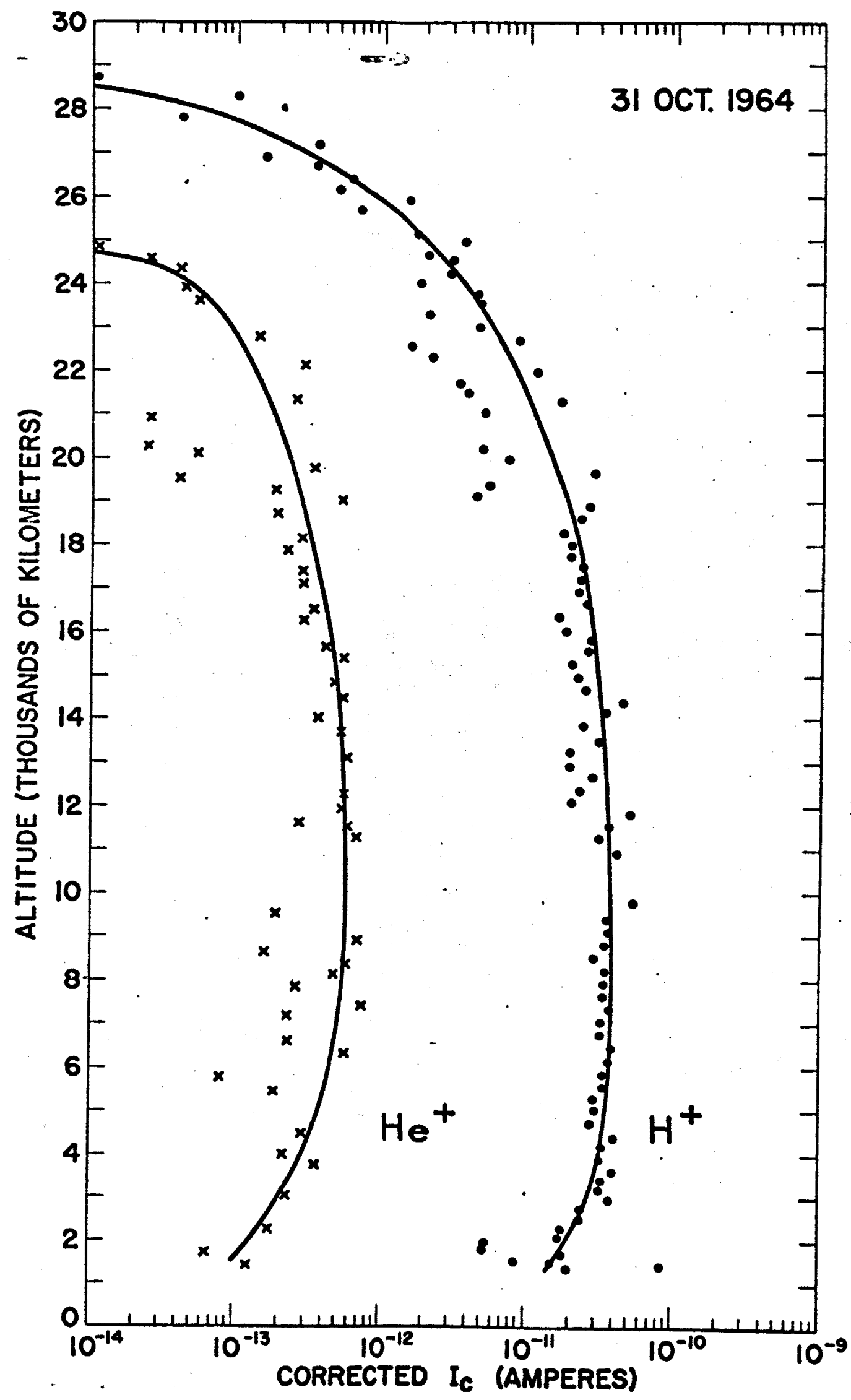

$F_{i g .8}$ 


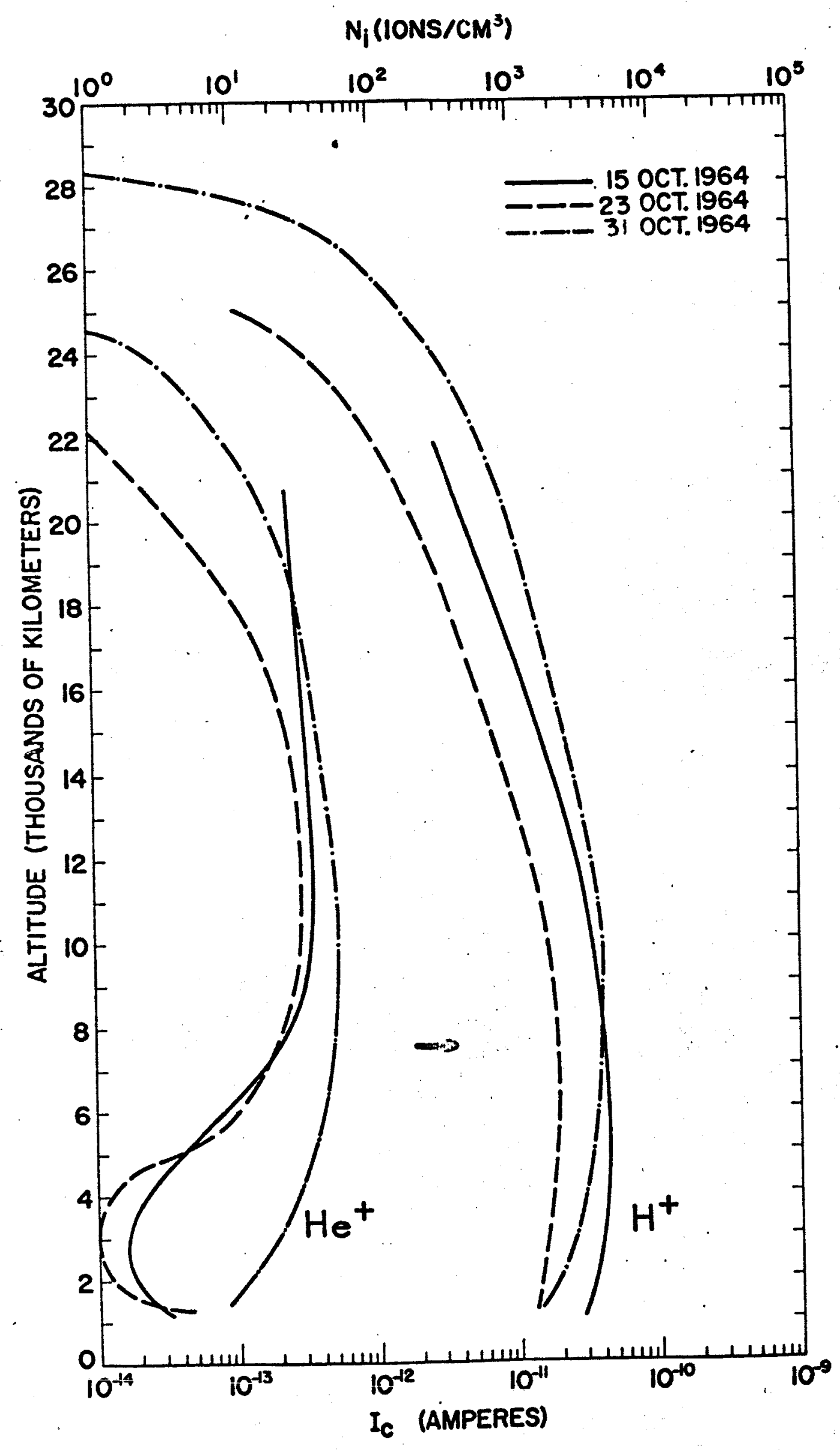




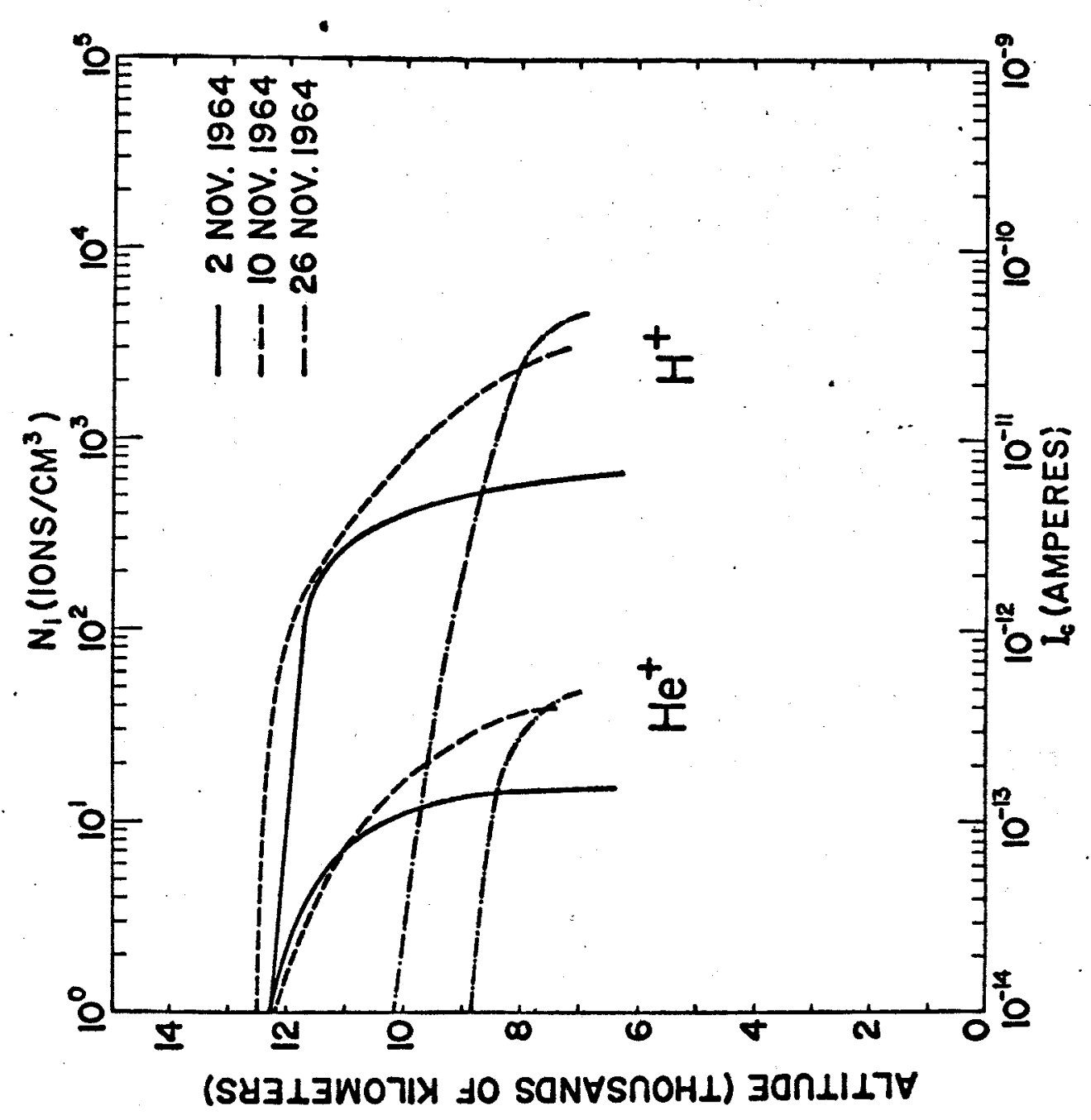

$\therefore$ Fig. 10 


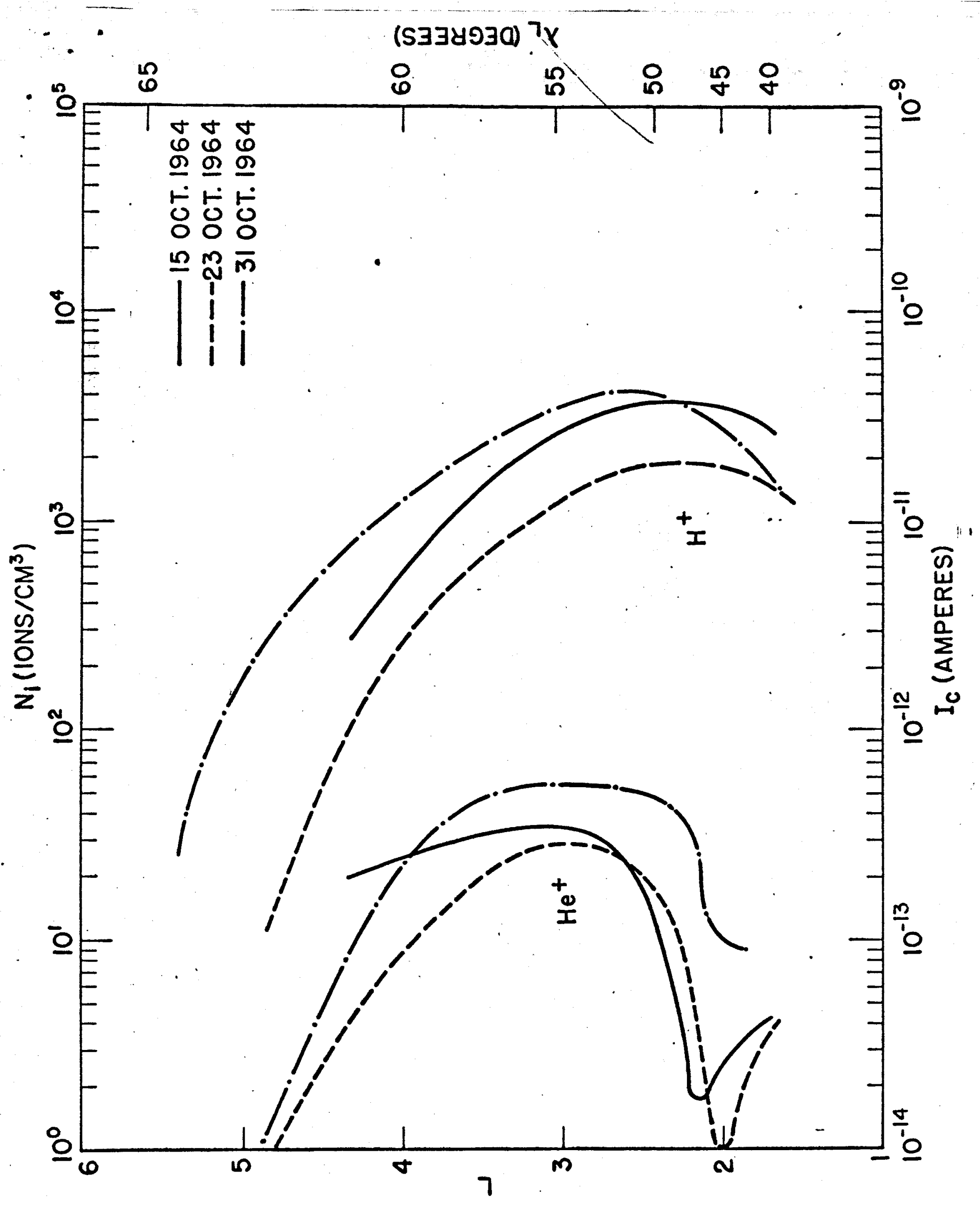




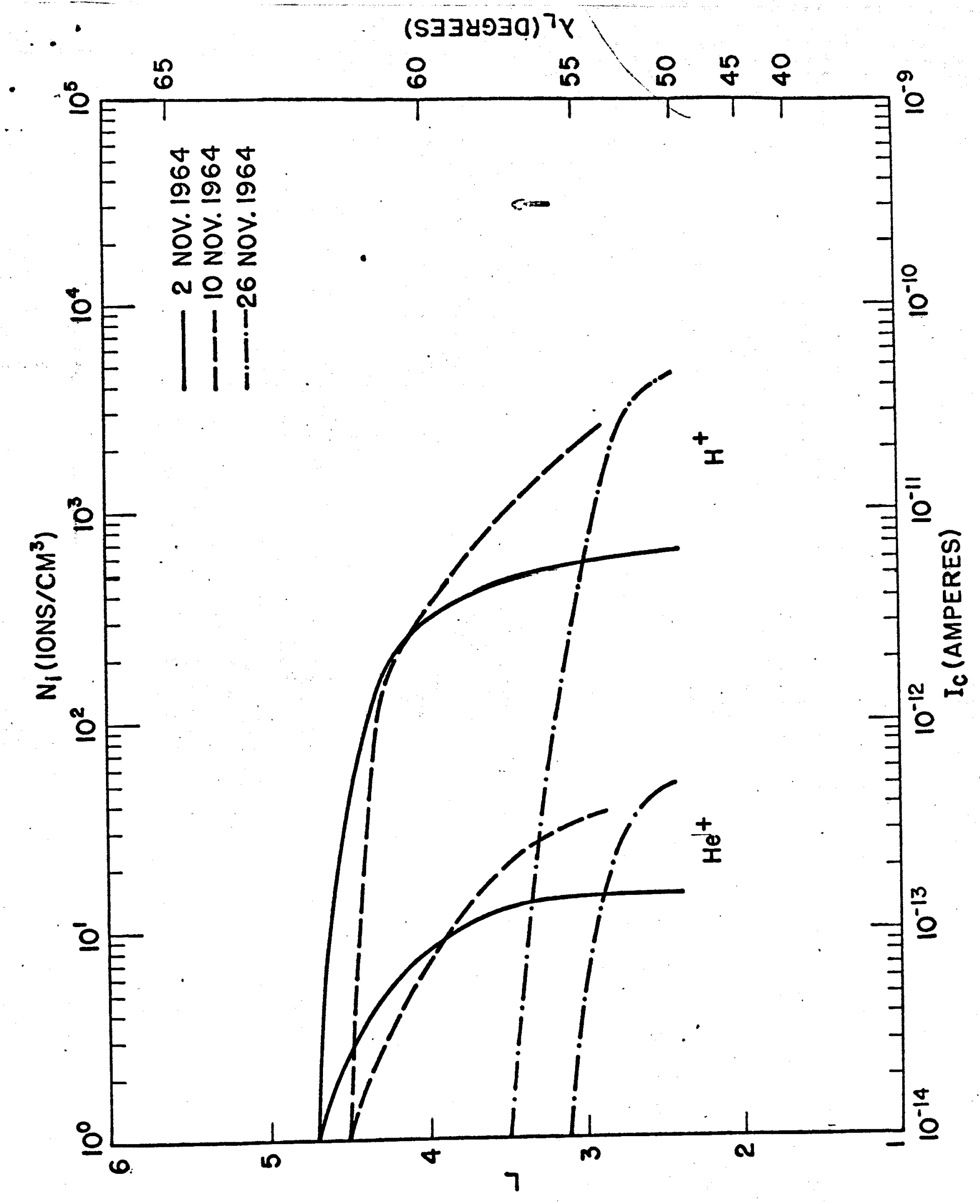




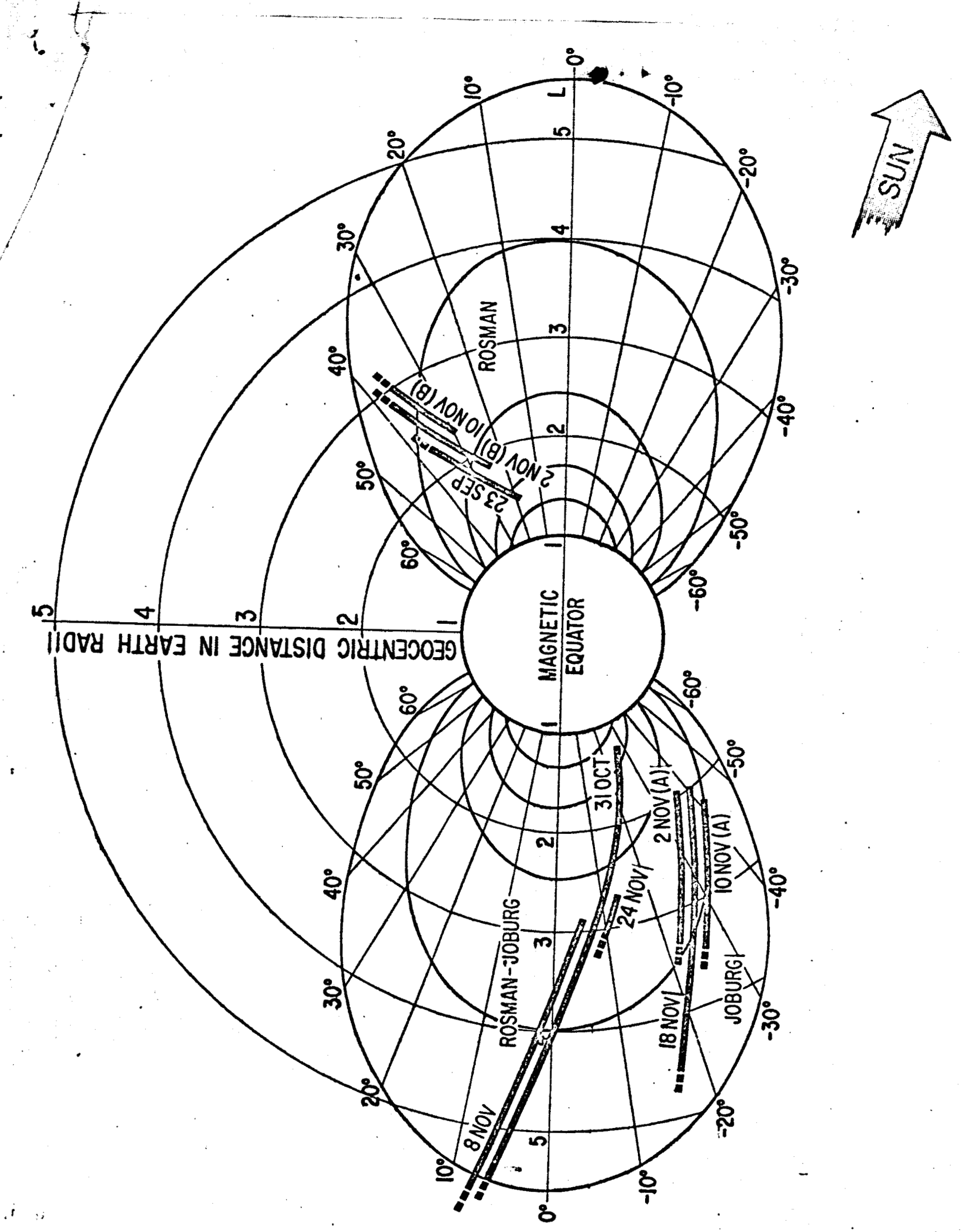




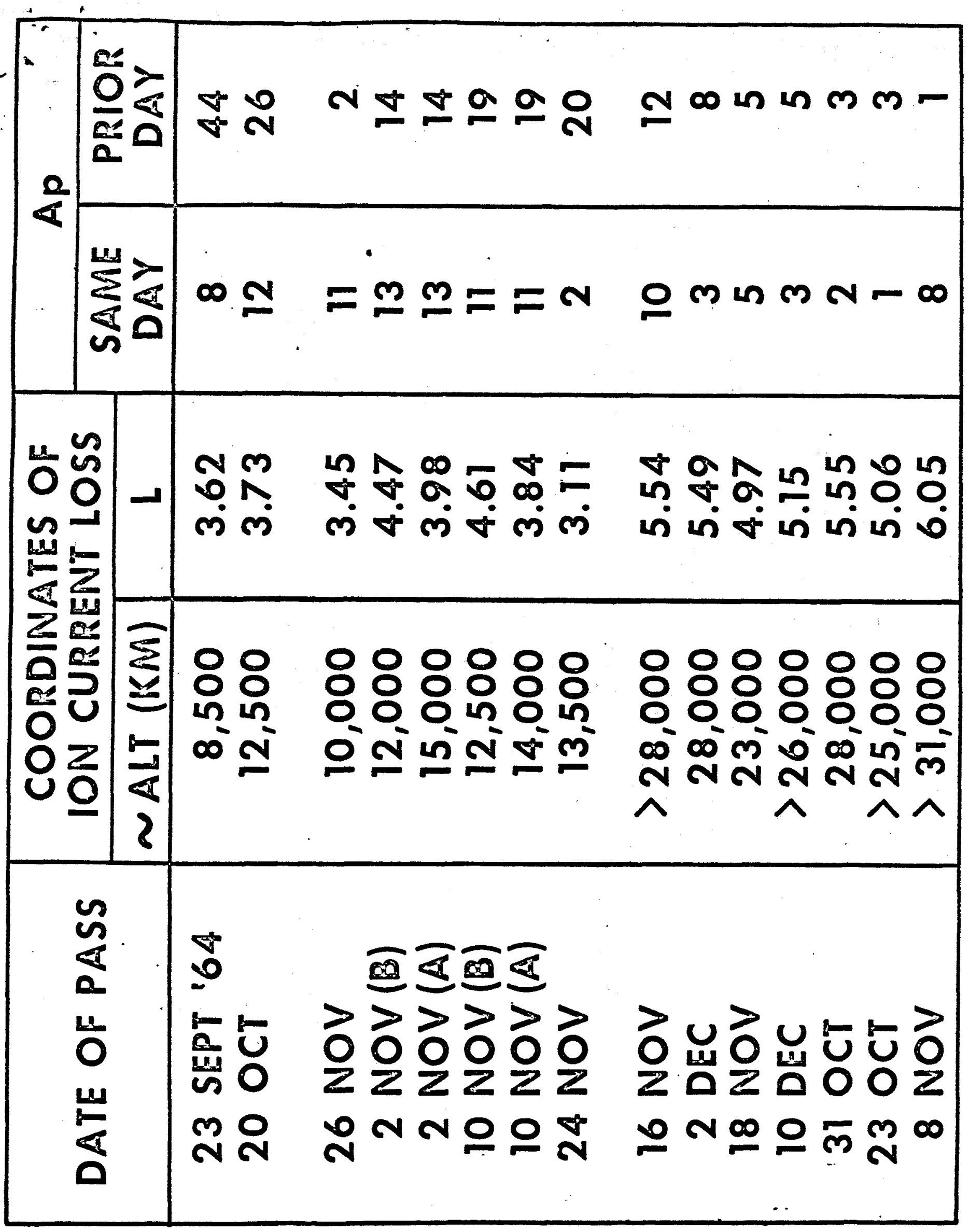

